\title{
Immunological Traits of Patients with Coexistent Inflammatory Bowel Disease and Periodontal Disease: A Systematic Review
}

\author{
João Martins de Mello-Neto ${ }^{1,+}{ }^{\dagger}$ Jessica Gomes Rodrigues Nunes ${ }^{2,+}$, Santosh Kumar Tadakamadla ${ }^{1}$ \\ and Carlos Marcelo da Silva Figueredo ${ }^{1, *(D)}$ \\ 1 School of Medicine and Dentistry, Menzies Health Institute Queensland, Griffith University, \\ Gold Coast, QLD 4222, Australia; j.martinsdemelloneto@griffith.edu.au (J.M.d.M.-N.); \\ s.tadakamadla@griffith.edu.au (S.K.T.) \\ 2 Department of Periodontology, Faculty of Odontology, Rio de Janeiro State University, \\ Rio de Janeiro 20551-030, Brazil; jessanunes@gmail.com \\ * Correspondence: c.dasilvafigueredo@griffith.edu.au; Tel.: +61-756780767 \\ + These two authors contributed equally.
}

check for updates

Citation: Mello-Neto, J.M.; Nunes, J.G.R.; Tadakamadla, S.K.; Figueredo, C.M. Immunological Traits of Patients with Coexistent Inflammatory Bowel Disease and Periodontal Disease: A Systematic Review. Int. J. Environ. Res. Public Health 2021, 18, 8958. https:// doi.org/10.3390/ijerph18178958

Academic Editor: Manabu Morita

Received: 21 July 2021

Accepted: 23 August 2021

Published: 25 August 2021

Publisher's Note: MDPI stays neutral with regard to jurisdictional claims in published maps and institutional affiliations.

Copyright: (c) 2021 by the authors. Licensee MDPI, Basel, Switzerland. This article is an open access article distributed under the terms and conditions of the Creative Commons Attribution (CC BY) license (https:// creativecommons.org/licenses/by/ $4.0 /)$.

\begin{abstract}
This systematic review assessed studies that evaluated the immunological traits of patients with both inflammatory bowel disease (IBD) and periodontal disease. An electronic search for literature was conducted on PubMed, Embase, Scopus, Cochrane and Web of Science. Studies that evaluated the immunological response in patients with IBD and periodontal disease were considered eligible for inclusion. A total of 6 cross-sectional studies of 275 patients were included. Immunological analyses were performed in gingival crevicular fluid, saliva, serum, intestinal and gingival biopsies. Four studies identified that the presence of IBD and periodontal disease was associated with higher levels of prostaglandin E2, aMMP8, IL-18 and S100A12, respectively, when compared to patients without the coexistence of both diseases. Furthermore, another study identified higher aMMP-8 levels with increasing severity of periodontitis in Crohn's disease patients. The quality of overall evidence ranged from high to low due to the observational nature of contributing studies. The coexistence of IBD and periodontal disease seems to be associated with a more responsive inflammatory reaction compared with individuals having one or the other. More randomized controlled studies evaluating the coexistence of IBD and periodontitis are required to better explore the immunological interplay between them.
\end{abstract}

Keywords: inflammatory bowel disease; ulcerative colitis; Crohn's disease; gingivitis; periodontitis; systematic review

\section{Introduction}

Inflammatory bowel disease (IBD), an umbrella term for Ulcerative colitis (UC) and Crohn's disease (CD), is a complex chronic inflammatory condition of the gastrointestinal tract [1]. Symptoms of IBD vary depending on the location and severity of inflammation and involve diarrhea, bleeding ulcers, stomach pain, cramping, bloating, weight loss and anemia, which might cause a debilitating condition with social and economic impacts [2] Despite limited epidemiological data from developing nations, both the incidence and prevalence of IBD are increasing worldwide [3]. The pathophysiology behind IBD has been under intense research, and much of it is still unknown. Nevertheless, currently, the disease is the result of an inappropriate immune response against environmental factors, including luminal and microbial antigens, in genetically susceptible hosts [1].

Evidence has shown that IBD patients are at higher risk of periodontitis and are more frequently edentulous than controls [4,5]. In addition, recent systematic reviews with meta-analyses have also confirmed the association between IBD and periodontitis [4,6-8]. Periodontitis occurs as an aberrant immunological response against the constant polymicrobial biofilm challenge, leading to attachment loss and, in severe cases, tooth loss [9]. Its 
severe form, which can lead to tooth loss, affects around 796 million people worldwide, making it the 11th most prevalent disease in human beings $[10,11]$.

The persistence and dysregulation of the host immune and inflammatory responses are mainly responsible for the tissue destruction in both IBD and periodontal disease [12,13], and the inflammatory response activation might be the link between them [14]. In fact, the activity of IBD influences the inflammatory response not only in the intestinal tissue but also causes systemic inflammation as demonstrated by the higher levels of TNF- $\alpha$ and IL-17 in the blood of patients with IBD in comparison to patients without IBD or those in disease remission [15-17]. Regarding periodontal disease, patients with severe periodontitis have elevated levels of inflammatory mediators (such as IL-1, IL-6, C-reactive protein (CRP) and fibrinogen) and increased neutrophil numbers in the blood when compared with healthy controls, contributing to the perpetuation of the patient's inflammatory state [18-20]. These observations have generated the hypothesis that IBD and periodontal diseases have a bidirectional relationship where one disease might worsen the other [21]. Hajishengallis and Chavakis [18] have highlighted that oral pathobiont-reactive T cells (enriched in Th17 cells), which expand during periodontitis, migrate through the lymphatics to the gut, where they are activated by the ectopically colonized oral pathobionts upon their processing by antigen-presenting cells. In fact, an important in vivo study has found that oral inflammation, such as ligature induced periodontitis, exacerbates gut inflammation by supplying the gut with both colitogenic pathobionts and pathogenic T cells [22]. Recently, a scoping review has assessed the microbiological and immunological association between both diseases [23]. However, this is the first systematic review to solely investigate the immunological pathway. Therefore, the present systematic review was conducted to answer a clearly formulated question: Does the coexistence of IBD and periodontal disease influence the traits of the immunological response?

\section{Materials and Methods}

The reporting of this review complies with the Preferred Reporting Items for Systematic Reviews and Meta-Analyses (PRISMA) statement guidelines [24]. The study was registered in PROSPERO (REF: CRD42021254507).

\subsection{Literature Search Strategy}

Two independent reviewers (JMMN and JGRN) conducted an electronic search through December 21, 2020, using Medical Subject Headings and other free terms or keywords on PubMed to access Medline. The search strategy was adapted to other electronic databases, including Embase, Scopus, Cochrane and Web of science; search was restricted to articles published in English. Appropriate Boolean operators (OR, AND) were used to refine the searches. Search strategy used in PubMed was: $(((($ inflammatory bowel diseases) OR (ulcerative colitis)) OR (Crohn's disease)) OR (Crohns disease)) OR (Colitis))) AND $(((((()(($ periodontal diseases) OR (periodontitis)) OR (aggressive periodontal disease)) OR (periodontitis aggressive)) OR (chronic periodontitis)) OR (chronic periodontal disease)) OR (gingival diseases)) OR (gingivitis)) OR (teeth loss)) OR (tooth loss) AND (english[Filter]).

The search strategy of the other databases is presented in the Supplementary Material S1. A further manual search was conducted by reviewing the reference lists of the relevant review articles. The titles and abstracts of the resulting articles were independently screened by two reviewers (JMMN and JGRN). Those articles found to be relevant on abstract screening were reviewed in full. Disagreement between reviewers was resolved through discussion. When an agreement could not be reached, a third reviewer (CMSF) was consulted. Pre-piloted forms were independently used for data extraction by two researchers (JMMN and JGRN), which was checked for accuracy by a third reviewer (CMSF). Data on the study design, matched variables, participants (sex distribution, age, ethnicity, other systemic diseases), periodontal disease definition, type of assay, immunological analyses, sample type, collection tool, storage temperature, immunological outcomes included 
in the study and their effect on periodontal outcomes were extracted. When important data in the retrieved articles were missing, an attempt was made to contact the authors.

\subsection{Focus Question}

In accordance with the PE (I) CO framework [24], we used the focus question, "Does the coexistence of IBD and Periodontitis influences the traits of the immunological response?"

- Population: IBD patients, periodontal disease patients and patients with both diseases

- Exposure/Intervention: Coexistence of periodontal disease and IBD

- Comparison: Subjects with solely IBD or periodontal disease or healthy controls

- Outcomes: Immunological evaluation

\subsection{Inclusion Criteria}

Case-control, cross-sectional, longitudinal, and cohort studies in humans that evaluated immunological changes in gingival crevicular fluid, blood, saliva, feces and/or biopsies of patients with IBD and periodontitis were considered for inclusion.

\subsection{Exclusion Criteria}

Studies that did not evaluate immunological changes in patients with periodontitis and IBD and studies that evaluated only the immunological outcomes in IBD or periodontal diseases alone. Conference abstracts, opinion pieces, reviews and editorials were also excluded.

\subsection{Assessment of Bias within Studies}

As only cross-sectional studies ended up being included in this systematic review, the original Newcastle-Ottawa Scale (NOS maximum 9 stars) was modified (maximum 8 stars) to assess the quality of these studies [25]. The detailed assessment of quality for all included studies was conducted by two reviewers independently (JMMN and JGRN) based on the NOS criteria adapted for cross-sectional studies by Zhao et al. [25]. Any discrepancies were resolved by discussion. The following study aspects were evaluated: representativeness of the sample, sample size, ascertainment of exposure, non-response rate, comparability, assessment of the outcome and statistical analysis. Each cross-sectional study could be awarded a maximum of eight stars. If a study fulfilled the description followed by a star, then this symbol was assigned to that study. Therefore, a percentage score based on the overall stars awarded was calculated. Those with $80 \%$ or higher scores were classified as high methodological quality, $51-79 \%$ scores were graded as moderate quality, and the studies with scores of $50 \%$ or lower were deemed to be of low quality [26].

Data were pooled into tables, and a descriptive summary was created to determine the quantity of data and study variations (characteristics and results). The information from the included studies was tabulated according to study designs, subject characteristics, sample characteristics, cytokines investigated and the main outcomes.

\section{Results}

The electronic search of the databases identified a total of 2112 papers as follows: Medline $(n=347)$, Embase $(n=672)$, Scopus $(n=686)$, Cochrane $(n=17)$, Web of Science $(n=390)$. All the relevant articles identified through the manual search were observed in the articles retrieved through the electronic search. After the elimination of duplicates and analyses of the titles and abstracts, 85 full texts were analyzed (Figure 1). Finally, six articles were included in the qualitative analysis [27-32]. Supplementary Material Table $\mathrm{S} 1$ depicts the excluded studies. The Kappa test statistic was 1.0 for the studies analyzed, indicating no disagreement between the reviewers. 


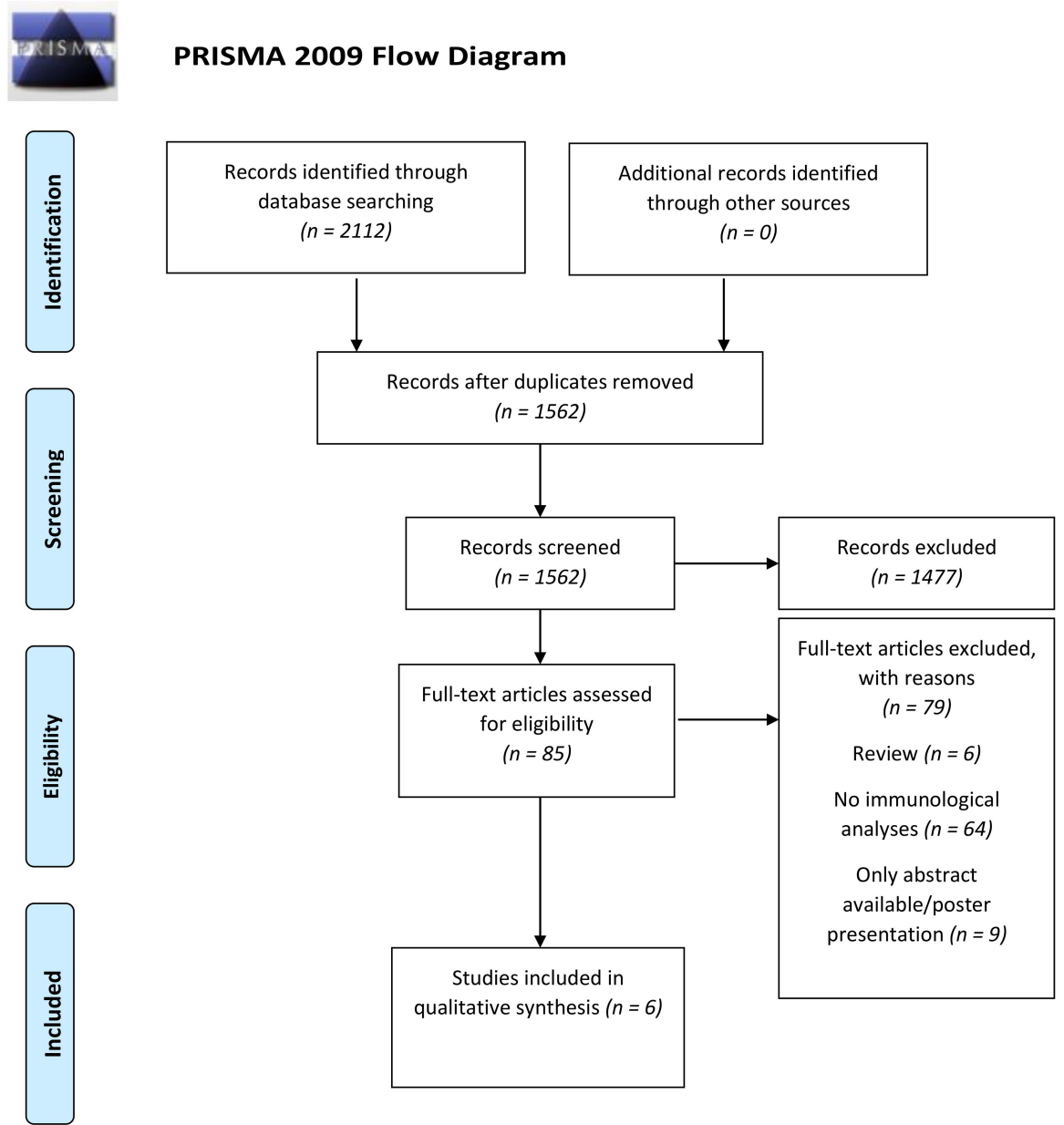

Figure 1. PRISMA Flowchart of the online databases searched and selection of studies for inclusion.

\subsection{Background Characteristics of the Included Studies}

In total, six cross-sectional studies were included in this systematic review. A total number of 275 individuals were included in the reviewed studies. Of those, 176 were diagnosed with IBD (166 exhibit IBD and periodontal disease and 10 IBD patients without a diagnosis of periodontal disease). In the remaining 99 patients, 89 had periodontal disease only, and 10 were healthy controls. The studies assessed immunological changes in subjects in GCF [27-29], serum [27,28], saliva [30], gingival biopsies [31,32] and intestinal biopsies [31,32]. Different methods of analysis (three studies used ELISA assay while Luminex assay and radioimmunoassay were used by two and one study, respectively) were used to evaluate the role of cellular immune response in the presence of both IBD and periodontitis. Analysis of the geographic distribution revealed that four studies were carried out in Brazil [28,30-32] and one each in the United States [27] and Germany [29]. None of the studies performed a power calculation. Four studies identified that the coexistence of IBD and periodontal disease is associated with higher levels of pro-inflammatory molecules when compared to patients with one or the other [27-30]. One study showed that the activity of IBD increases the levels of IL-4, IL-10 and IL-21in the periodontal tissue [31]. A second study showed higher levels of Interleukin (IL)-17A, IL-17F, IL-22, IL-25, IL-33, Interferon (INF)-g and IL-10 in gingival tissue, as well as a tendency for higher levels of IL-6, IL-31 and IL-21 when compared with intestinal tissue [32]. Table 1 summarizes the included studies that evaluated possible common immunological features between IBD and periodontal disease. Table 2 highlights the periodontal findings. Due to the high methodological and clinical heterogeneity between the studies, it was not possible to perform a meta-analysis. 
Table 1. Characteristics of the included studies.

\begin{tabular}{|c|c|c|c|c|c|c|c|}
\hline Author (Year) & $\begin{array}{l}\text { Matched } \\
\text { Variables }\end{array}$ & Participants & $\begin{array}{l}\text { Medicaments/Smoking } \\
\text { Habits/Disease Activity }\end{array}$ & $\begin{array}{c}\text { Periodontal and IBD } \\
\text { Diagnose }\end{array}$ & Type of Essay & Sample & Main Immunological Outcomes \\
\hline $\begin{array}{c}\text { Van Dyke et al., } \\
1986\end{array}$ & Age and gender. & $\begin{array}{l}\text { IBD patients with }(n=10) \\
\text { and without }(n=10) \\
\text { periodontal disease } \\
\text { Patients with periodontitis } \\
(n=8) \\
\text { Healthy controls }(n=8)\end{array}$ & $\begin{array}{c}\text { Steroid therapy } \\
\text { Subjects were not included if } \\
\text { they smoked } \\
\leq 10 \text { cigarettes daily. } \\
\text { No disease activity information }\end{array}$ & $\begin{array}{l}\text { Gingival erythema, edema, } \\
\text { suppuration, BOP, pain } \\
\text { upon probing, Ramfijord } \\
\text { attachment levels and } \\
\text { Periapical X-ray. } \\
\text { IBD: combination of } \\
\text { symptoms, including } \\
\text { diarrhea, abdominal pain, } \\
\text { bleeding, weight loss, } \\
\text { perianal disease, } \\
\text { and arthritis. } \\
\text { Control: healthy } \\
\text { individuals who had no } \\
\text { bone loss or } \\
\text { no/mild gingivitis. }\end{array}$ & $\begin{array}{l}\text { Radioimmunoassay: PGE2 } \\
\text { Phagocytosis: Van } \\
\text { Furth method } \\
\text { Boyden chamber assay. } \\
\text { Neutrophils } \\
\text { Chemotaxis assay. }\end{array}$ & $\begin{array}{c}\text { GCF } \\
\text { Serum }\end{array}$ & $\begin{array}{l}\text { PGE2 sig. > in GCF of IBD patients with } \\
\text { periodontitis compared to matched } \\
\text { adult periodontitis. } \\
\text { Chemotactic response sig < in UC patients with } \\
\text { periodontal disease compared to healthy patients. } \\
\text { The chemotactic response of normal neutrophils } \\
\text { was significantly inhibited by all serum from } \\
\text { patients with IBD and periodontal disease. The } \\
\text { chemotactic response of normal neutrophils was } \\
\text { not affected by serum from normal donors. } \\
\text { IBD patients without the periodontal disease had } \\
\text { mixed results. } \\
\text { Neutrophil phagocytosis was similar between } \\
\text { the groups. }\end{array}$ \\
\hline $\begin{array}{l}\text { Figueredo et al., } \\
2011\end{array}$ & Age, gender. & $\begin{array}{l}\text { CD patients with } \\
\text { periodontitis }(n=15) \\
\text { UC patients with } \\
\text { periodontitis } \\
(n=15) \\
\text { Periodontitis patients } \\
(n=15)\end{array}$ & $\begin{array}{l}\text { CD: immunomodulators }(n=7), \\
\text { aminosalicylates }(n=4) \text { and } \\
\text { immunomodulator }+ \\
\text { aminosalicylates }(n=2) . \\
\text { UC: immunomodulators }(n=1), \\
\text { aminosalicylates }(n=9) \text { and } \\
\text { immunomodulators }+ \\
\text { aminosalicylates }(n=5) . \\
\text { CD }(n=3), \text { UC }(n=1) \text { and } \\
\text { controls }(n=2) \text { were smokers. } \\
\text { UC: active disease }(n=3) \text { and } \\
12 \text { in remission. } \\
\text { CD: active disease }(n=5) \\
\text { remission }(n=10) .\end{array}$ & $\begin{array}{l}\text { At least five inflamed sites } \\
\text { with PD of } \geq 5 \mathrm{~mm} \text { and } \\
\text { CAL of } \geq 3 \mathrm{~mm} \text { in different } \\
\text { teeth and diagnosed with } \\
\text { chronic untreated } \\
\text { Periodontitis. } \\
\text { CD and UC: outpatients } \\
\text { already diagnosed with } \\
\text { IBD attending the } \\
\text { Gastroenterology clinics. }\end{array}$ & $\begin{array}{c}\text { ELISA for IL-18. } \\
\text { Multiplex assay for IL-1 } \beta, \\
\text { IL-4, IL-6, IL-10, IL-12p40, } \\
\text { IL-12p70, TNF- } \alpha \text { and } \\
\text { IFN- } \gamma .\end{array}$ & $\begin{array}{c}\text { GCF } \\
\text { Serum }\end{array}$ & $\begin{array}{c}\text { IL-4 sig. < in deep sites of patients with CD and } \\
\text { periodontitis compared to periodontitis only. UC } \\
\text { patient }<\text { total amount of IL-4 in the GCF in the } \\
\text { shallow site and a > IL- } 6 \text { in deep sites, when } \\
\text { compared with periodontitis only. } \\
\text { Serum levels of IL-18 sig. > in patients with the } \\
\text { coexistence of IBD and periodontitis. } \\
\text { Positive correlation between IL-6 in GCF and } \\
\text { IFN- } \gamma \text { in serum of CD patients. } \\
\text { Positive correlation between IL- } 1 \beta \text { in gingival } \\
\text { crevicular fluid and IL- } 18 \text { in serum of UC patients. } \\
\text { No correlation was observed in periodontitis only. }\end{array}$ \\
\hline $\begin{array}{c}\text { Figueredo et al., } \\
2017\end{array}$ & Age and gender. & $\begin{array}{l}\text { DC patients with } \\
\text { periodontitis }(n=10) \\
\text { UC patients with } \\
\text { periodontitis }(n=11) \\
\text { No control group } \\
\text { without IBD. }\end{array}$ & $\begin{array}{l}\text { Mesalazine }(n=7) \text {, mesalazine } \\
\text { + azathioprine }(n=8), \\
\text { mesalazine, azathioprine }+ \\
\text { TNF } \alpha \text { inhibitor }(n=4) \text { and } \\
\text { mesalazine }+ \text { steroid }(n=2) \text {, } \\
\text { Smoking habits not reported } \\
\text { CD }(n=4) \text { and UC }(n=4) \text { had } \\
\text { active disease and CD }(n=6) \\
\text { and UC }(n=7) \text { were } \\
\text { in remission. }\end{array}$ & $\begin{array}{l}\text { At least } 10 \text { teeth with } \\
\text { PD } \geq 5 \mathrm{~mm} \text { and } \\
\mathrm{CAL} \geq 4 \mathrm{~mm} \text { in at least } \\
4 \text { sites, in different teeth. } \\
\text { IBD: clinical, endoscopic, } \\
\text { radiologic, and } \\
\text { histological parameters. }\end{array}$ & $\begin{array}{c}\text { Multiplex assay for IL-1 } \beta, \\
\text { IL-4, IL-6, IL-10, IL-21, } \\
\text { IL-22, IL-23, IL-25, IL-31, } \\
\text { IL-33, IL-17A, IL-17, } \\
\text { IFN- } \gamma \text {, sCD40L, and } \\
\text { TNF- } \alpha \text {. }\end{array}$ & $\begin{array}{c}\text { Gingival and } \\
\text { Intestinal tissues }\end{array}$ & $\begin{array}{l}\text { Cytokine levels were similar in intestinal tissue } \\
\text { between CD and UC patients. } \\
\text { IL-23 in gingival tissue in CD sig. > compared to } \\
\text { UC patients with periodontitis. } \\
\text { IL-4, IL-10, and IL-21 levels in gingival tissue sig. > } \\
\text { inactive IBD. Furthermore, a trend towards > } \\
\text { IL-1 } \beta \text { levels. } \\
\text { IL-1 } \beta, \text { IL-4, IL-6, IL-17A, IL17, IL-21, IL-31, IL-33, } \\
\text { and sCD40L were sig. > in intestinal tissue from } \\
\text { patients with active disease. Furthermore, a trend } \\
\text { towards increased levels of TNF- } \alpha \text { inactive IBD. }\end{array}$ \\
\hline
\end{tabular}


Table 1. Cont.

\begin{tabular}{|c|c|c|c|c|c|c|c|}
\hline Author (Year) & $\begin{array}{l}\text { Matched } \\
\text { Variables }\end{array}$ & Participants & $\begin{array}{l}\text { Medicaments/Smoking } \\
\text { Habits/Disease Activity }\end{array}$ & $\begin{array}{c}\text { Periodontal and IBD } \\
\text { Diagnose }\end{array}$ & Type of Essay & Sample & Main Immunological Outcomes \\
\hline $\begin{array}{l}\text { Schmidt et al., } \\
2018\end{array}$ & Age and gender. & $\begin{array}{l}\text { CD patients with } \\
\text { periodontal disease }(n=30) \\
\text { UC patients with } \\
\text { periodontal disease }(n=29) \\
\text { Controls }(n=59)\end{array}$ & 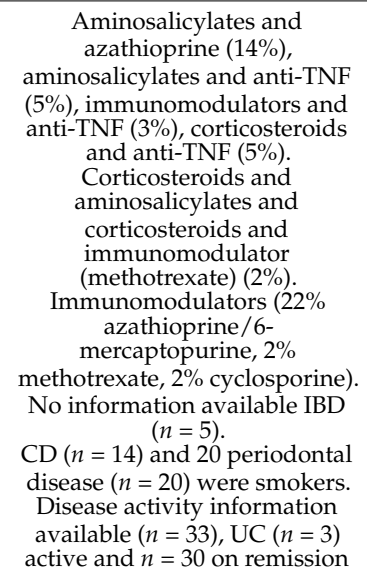 & $\begin{array}{l}\text { Periodontal condition was } \\
\text { classified into } \\
\text { healthy/mild, moderate } \\
\text { or severe } \\
\text { Periodontitis. No } \\
\text { assessment of bleeding on } \\
\text { probing (BOP). Papilla } \\
\text { bleeding index (PBI). } \\
\text { IBD: outpatients recruited } \\
\text { within a private } \\
\text { gastroenterological clinic. }\end{array}$ & ELISA assay for aMMP-8 & GCF & $\begin{array}{l}\text { aMMP-8 in IBD sig. > compared to control. } \\
\text { No sig. difference between CD and UC. } \\
\text { aMMP-8 in CD sig. > with increasing severity } \\
\text { of periodontitis. } \\
\text { Periodontitis severity had no influence on } \\
\text { aMMP-8 in UC and controls. } \\
\text { aMMP } 8 \text { > in patients with } \\
\text { severe periodontitis and CD compared to UC and } \\
\text { HC also with severe periodontitis. } \\
\text { aMMP-8 in CD patients with no or mild } \\
\text { periodontitis was < than in the case of UC. }\end{array}$ \\
\hline $\begin{array}{l}\text { Manegat et al., } \\
2016\end{array}$ & Age and gender. & $\begin{array}{l}\text { DC patients with } \\
\text { periodontitis }(n=18) \\
\text { UC patients with } \\
\text { periodontitis }(n=10) \\
\text { No control group } \\
\text { without IBD. }\end{array}$ & $\begin{array}{c}\text { CD: immunomodulators } \\
(n=13), 5 \text {-aminosalicylate } \\
\text { derivatives }(n=11), \\
\text { corticosteroids }(n=1), \\
\text { immunomodulatory } \\
\text { derivatives + 5-aminosalicylate } \\
(n=10) \text { no medication }(n=4) \text {. } \\
\text { UC: } 5 \text {-aminosalicylate } \\
\text { derivatives }(n=8), \\
\text { immunomodulators }(n=5), \\
\text { corticosteroids }(n=1) \text { and } \\
\text { immunomodulatory } \\
\text { derivatives + 5-aminosalicylate } \\
\text { acid derivatives }(n=4) \text { no } \\
\text { medication }(n=1) \\
\text { CD group had two smokers } \\
\text { and one ex-smoker and UC had } \\
\text { three ex-smokers. } \\
\mathrm{CD}(n=1) \text { and UC }(n=2) \text { with } \\
\text { disease active. }\end{array}$ & $\begin{array}{l}\text { At least } 8 \text { teeth with } \\
\mathrm{PD} \geq 5 \mathrm{~mm} \text { and } \mathrm{CAL} \geq 4 \\
\mathrm{~mm} \text { in at least } 4 \text { sites, in } \\
\text { different teeth. } \\
\text { IBD: clinical, endoscopic, } \\
\text { radiologic, and } \\
\text { histological parameters. }\end{array}$ & $\begin{array}{l}\text { LUMINEX for IFN- } \gamma, \\
\text { IL-1 } \beta \text {, IL-4, IL-6, IL-10, } \\
\text { IL-21, IL-22, IL-23, IL-25, } \\
\text { IL-31, IL-33, IL-17A, IL-17F, } \\
\text { sCD40L, and TNF- } \alpha\end{array}$ & $\begin{array}{c}\text { Gingival and } \\
\text { intestinal tissues }\end{array}$ & $\begin{array}{l}\text { No differences in cytokine levels between CD and } \\
\text { UC patients in the gingival tissue. } \\
\text { IL-17A, IL-17F, IL-22, IL-25, IL-33, INF-g, and } \\
\text { IL-10 sig. > in gingival tissue. } \\
\text { IL-6, IL-31 and IL-21 in gingival tissue showed a } \\
\text { tendency to > levels compared to intestinal tissue. }\end{array}$ \\
\hline $\begin{array}{l}\text { Figueredo et al., } \\
2021\end{array}$ & Age, gender. & $\begin{array}{c}\text { CD patients with } \\
\text { periodontitis }(n=9) \\
\text { UC patients with } \\
\text { periodontitis }(n=9) . \\
\text { Periodontitis patients }(n=5) .\end{array}$ & Not reported & Not reported & ELISA for S100A12 & Saliva & $\begin{array}{l}\text { S100A12 sig. > in patients with UC patients with } \\
\text { periodontitis compared to CD } \\
\text { and non-IBD patients also with periodontitis. }\end{array}$ \\
\hline
\end{tabular}

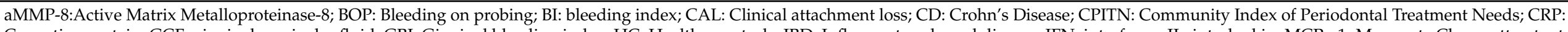

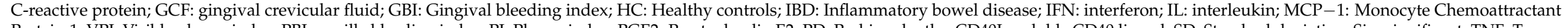

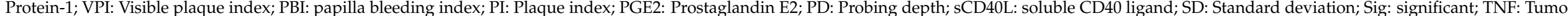
necrosis factor; UC: Ulcerative colitis. 
Table 2. Periodontal characteristics of the included studies.

Author (Year)

Van Dyke et al., 1986

Figueredo et al., 2011

Figueredo et al., 2017

Schmidt et al., 2018

Figueredo et al., 2021 Menegat et al., 2016

\section{Periodontal Findings}

Comparison of IBD periodontitis and periodontitis groups revealed no significant differences in CAL. Periodontal health of the IBD patient is one of moderate to severe periodontitis with extreme inflammation compared with periodontitis only. Redness Bleeding, CAL and PPD were significant > in IBD with periodontitis and adult periodontitis compared to IBD with no periodontitis and controls. CAL, BOP, PI and GCF volume did not differ between the groups. PI, BOP, PD, CAL did not differ between the groups.

Significant higher CAL was found in IBD compared to HC, but no significant difference was found for PPD. The PBI was significantly higher in IBD than in HC. IBD group significantly had more participants with severe periodontitis compared to HC. Periodontal parameters did not significantly differ between CD and UC.

Not reported

CD patients presented higher \% PD significant $>7 \mathrm{~mm}$ compared to UC patients also with periodontitis.

BOP: Bleeding on probing; BI: Bleeding index; CAL: Clinical attachment loss; CD: Chron's Disease; HC: Healthy controls; IBD: Inflammatory bowel disease; PBI: Papilla bleeding index; PI: Plaque index; PPD: Probing pocket depth.

\subsection{Results from Individual Studies}

- Immunological changes in GCF

The immunological analysis of GCF was performed in three studies [27-29]. One study detected Prostaglandin E2 (PGE2) levels four times higher in the group with IBD and periodontal diseases when compared to the matched periodontitis patients [27]. A second study identified higher levels of aMMP-8 in severe periodontitis patients with $\mathrm{CD}$ compared to $\mathrm{UC}$ and healthy controls also with severe periodontitis. Indeed, in CD aMMP-8, values increased significantly with increasing severity of periodontitis [29]. A third one has shown that the total amount of IL-4 was significantly lower in shallow sites from IBD patients with periodontitis compared to non-IBD patients with periodontitis [28].

- $\quad$ Systemic Immunological changes

The systemic immunological evaluation in the presence of both diseases was performed in two studies. One study identified higher levels of IL-8 in serum of patients with both diseases compared to periodontitis only [28]. In addition, a second study also demonstrated the chemotactic response of normal neutrophils to be significantly inhibited by serum from patients with IBD and periodontal disease. The chemotactic response of normal neutrophils was not affected by serum from healthy donors. Regarding IBD patients without periodontal disease, there were mixed results, with two of six Crohn's disease patients and two of four ulcerative colitis patients exhibiting defects. In addition, patients with Ulcerative colitis exhibited reduced chemotactic response [27].

- Salivary changes in patients with IBD and periodontitis

Only one study with a high risk of bias evaluated immunological changes in the saliva of patients having both diseases [30]. Higher expression of S100A12 was found in patients with UC with chronic periodontitis when compared to non-IBD and CD patients also with periodontitis [30].

- Subdivision of IBD patients with periodontitis into Ulcerative colitis and Crohn's disease

Although UC and CD are collectively known as IBD, the comparisons of immunological responses between these two distinct IBD entities (UC and CD) has been reported among all six studies. Van Dyke et al. pointed out that the chemotactic response of neutrophils in serum from patients with $C D$ who had periodontal disease was not different from healthy subjects. However, patients with UC exhibited reduced chemotactic response [27]. Regarding IBD patients without periodontal disease, there were mixed results, with two of six CD patients and two of four UC patients exhibiting reduced chemotactic response. Figueredo et al. have also recently shown that salivary levels of S100A12 were significantly 
higher in patients with UC compared to CD and non-IBD patients [30]. On the other hand, Figueredo et al. highlighted increased levels of IL-23 in gingival tissue in patients with CD in comparison to patients with UC [31]. Schmidt et al. also found that patients with severe periodontitis and CD show the highest aMMP-8 concentration compared to UC and healthy controls [29]. A fifth study also found immunological differences when comparing CD and UC patients also with periodontitis. CD patients showed a strong, significant positive correlation between IL-6 in gingival crevicular fluid and IFN-y in serum, and UC patients showed a significant, positive correlation between IL-1 $\beta$ in GCF and IL-18 in serum [28]. However, other authors in a study without controls did not find immunological differences between UC and CD patients also with periodontitis [32].

- Immunological changes in gingival and intestinal tissues

Two studies evaluated immunological changes in intestinal and gingival tissues [31,32]. High levels of IL-17A, IL-17F IL-22, IL-25, IL-33, IL-10 and INF-y were found in gingival biopsies compared with intestinal biopsies from patients with IBD and periodontitis [32]. Figueredo et al. found that the IBD activity (evaluated by chemical and laboratory parameters) significantly increased the expression of IL-4, IL-10 and IL-21 in gingival tissue of patients with periodontitis [31]. Regarding intestinal tissue analyses, higher levels of IL-1 $\beta$, IL-4, IL-6, IL-17A, IL17F, IL-21, IL-31, IL-33 and soluble CD40 ligand (sCD40L) were found in patients having IBD activity and periodontitis [31].

\subsection{Risk of Bias (Quality Assessment)}

Of the six studies included in this systematic review, one received a 3-point score out of a total of 8 points (low methodologic quality) [30]; three received 6-point scores [28,31,32]; two received 7-point scores (high quality) [27,29]; (Supplementary Material Table S2). Although none of the studies performed a sample calculation, one study showed a sample with high representativeness of periodontitis and IBD [29]. All studies described standardized, conventional immunological methods i.e., ELISA assay, Multiplex, chemotaxis and phagocytosis assay, but none reported blinding of examiners. All but one study [30] considered in this review reported adequate assessment of periodontal diseases conditions using clinical periodontal parameters (BOP, CAL, PD, GBI, CPITN); however, three studies did not report how the diagnosis of IBD was confirmed [27,28,31].

\section{Discussion}

The systemic impact of the coexistence of IBD and periodontitis has been evaluated in two studies $[27,28]$. Figueredo et al. showed that higher levels of IL-18 in serum of patients with both diseases when compared to patients with periodontitis only [28]. It is known that IL-18, together with IL-1 $\beta$, not only contributes to the host's defense against infections by activating phagocytes, such as monocytes, macrophages, dendritic cells and neutrophils, but also induces T-helper 17 (Th17)- and Th1-mediated adaptive immune responses [33]. However, the absence of a group with IBD and without periodontitis enables more comparisons as higher levels of IL-18 have been previously found in the plasma of patients with IBD, especially in CD [34]. Besides, Van Dyke et al. identified important alterations in neutrophils chemotactic response in the presence of both diseases [27]. It has been shown that dysfunctional neutrophil chemotaxis predisposes patients with periodontitis to neutrophil-mediated collateral host tissue damage [35]. In addition, one of the most obvious features in inflamed mucosa in IBD patients during the acute stage is the formation of crypts and abscesses, which results from the influx of neutrophils into the epithelial area and subsequently into the intestinal lumen [36]. Thus, chemotactic changes caused by the coexistence of IBD and periodontitis may impact the pathogenesis of both diseases. However, more studies are needed to confirm the systemic impacts of the coexistence of IBD and periodontitis.

Regarding the local impact of periodontitis, previous research has shown that decreased levels of IL-4 and increased levels of MMP-8, PGE2 and S100A12 in the oral cavity are associated with higher periodontal deterioration [37-40]. IL-4 is an anti-inflammatory 
cytokine that functions mainly by suppressing the pro-inflammatory milieu [41]. IL-4 plays a regulatory role in inhibiting Th1 responses, which are typified by cellular immune responses to intracellular pathogens [42]. Karttunen et al. [43] have previously reported that the frequency of IL-4-secreting mucosal cells is lower in IBD patients compared with controls. Thus, the significantly lower GCF levels of IL-4 in deep sites of IBD patients with periodontitis when compared with non-IBD patients with periodontitis may be associated with important immunological alterations when both diseases coexist [28]. Besides that, PGE2 regulates many physiological functions of the gut, including mucosal protection, gastrointestinal secretion and motility, inhibits fibroblast migration in intestinal wound healing and is implicated in the pathophysiology of IBD [44]. In the intestine of patients with IBD, aMMP8 are elevated and associated with neutrophil infiltration [45]. Taking together, the higher levels of aMMP- 8 and PGE2 identified with the coexistence of IBD and periodontitis and lower levels of IL-4 seems to alter immunological traits in GCF negatively. In addition, one study with a higher risk of bias highlighted higher expression of S100A12 in patients with UC and chronic periodontitis. S100A12 is a well-known biomarker used to differentiate IBD from Inflammatory bowel syndrome, and its levels are higher serum and feces of IBD patients [46,47]. Moreover, S100A12 is highly abundant in neutrophils during acute inflammation and has been implicated in immune regulation and IBD pathogenesis. Therefore, the increased salivary levels of S100A12 in patients with UC and periodontitis deserves to be further explored.

The evaluation of disease activity is critical in order to monitor and adjust therapy in patients with IBD [48]. Only one study evaluated the influence of IBD activity in the presence of periodontitis [31]. The IBD activity was associated with significantly increased expression of IL-4, IL-10 and IL-21 in the gingival tissue of patients with periodontitis. Regarding intestinal tissue analyses, higher levels of IL-1 $\beta$, IL-4, IL-6, IL-17A, IL17F, IL-21, IL-31, IL-33 and SCD40L were found in patients with IBD and periodontitis. These data add to evidence that IBD activity also affects the immunological response in the gingival tissue, which also merits further investigation concerning whether one disease can be affecting the progression of the other. However, a limitation of this study is the absence of a control group with one or no disease enabling further conclusions if the coexistence of both the diseases alters patient immunological traits.

The role of immunity and, in particular, the Th17 pathway in the periodontitis-IBD relationship has been recently highlighted by Kitamoto et al. [22]. The authors have shown that ligature induced periodontitis generates oral pathobiont-reactive Th17 cells that can migrate to the inflamed gut. These Th17 cells of oral origin can be activated by translocated oral pathobionts and cause the development of colitis when in the gut through IL-1 $\beta$ [22]. Indeed, Byrd et al. [14] have hypothesized that IBD can be driven by microbiomial and inflammatory changes originating specifically from the gingival niche through saliva, thereby worsening IBD outcomes and thus perpetuating a vicious cycle. In fact, a recent scoping review has found that periodontitis and IBD patients share similarities in their microbiological and immunological patterns [23]. However, we are the first to highlight through a systematic review the immunological changes that occur when IBD and periodontitis coexist in the same patient.

Besides, a higher inflammatory response in patients with periodontitis has been previously linked to the development of colorectal precursor lesions in observational studies [49]. The plausible mechanistic links between periodontal disease and cancer, includes chronic low-grade systemic inflammation, increased exposure to free radicals and active intermediates causing oxidative/nitrosative stress, but no mechanisms have been established yet, and more research may help gain a better understanding in this regard [50-52].

There are some limitations to our analysis. First, all six studies included in this systematic review are cross-sectional studies, and they cannot establish temporality. Furthermore, they do not help determine the cause-effect relationship between the diseases. Besides, our parameter here was based only on the total amount/concentration of given molecules. 
Second, the sample size in the included studies is small, limiting the generalizability of their findings. Third, four of the six studies come from the same research group, highlighting limited diversity of the origin of the studies. In addition, the lack of homogenous quantitative data for meta-analysis could be considered a drawback of the present systematic review. Fourth, the variability in diagnostic criteria for periodontitis and in the consideration of different potential confounders such as smoking, medications and activity of IBD could diminish the precision of this systematic review.

\section{Conclusions}

The coexistence of IBD and periodontal disease seems to be associated with a more responsive inflammatory reaction when compared with individuals having IBD or periodontal disease alone. On the basis of current data, the coexistence of both diseases might exacerbate the inflammatory response, and, therefore, more tissue destruction in both periodontal and intestinal tissue might be expected. More well-designed longitudinal studies with larger sample sizes and control groups, evaluating the immunological response as well as the impact of its treatment in the progression of both diseases, are required. Furthermore, confirmatory studies should be performed to evaluate if other inflammatory biomarkers are involved in the pathogenesis of both diseases.

Supplementary Materials: The following are available online at https:/ /www.mdpi.com/article/ 10.3390/ijerph18178958/s1, S1: Database Search Strategies, Table S1: Reasons for excluding after assessing eligibility criteria., Table S2: Risk assessment of included studies.

Author Contributions: Conceptualization, C.M.d.S.F.; methodology, J.M.d.M.-N., J.G.R.N., S.K.T. and C.M.d.S.F.; validation, J.M.d.M.-N. and J.G.R.N.; formal analysis, J.M.d.M.-N. and J.G.R.N.; investigation, J.M.d.M.-N. and J.G.R.N.; resources, J.M.d.M.-N. and J.G.R.N.; data curation, J.M.d.M.-N. and J.G.R.N.; writing — original draft preparation, J.M.d.M.-N. and J.G.R.N.; writing—review and editing, C.M.d.S.F., J.M.d.M.-N., J.G.R.N. and S.K.T.; visualization, C.M.d.S.F., J.M.d.M.-N., J.G.R.N and S.K.T.; supervision, C.M.d.S.F.; project administration, C.M.d.S.F.; funding acquisition, not applicable. All authors have read and agreed to the published version of the manuscript.

Funding: This research received no external funding.

Institutional Review Board Statement: Not applicable.

Informed Consent Statement: Not applicable.

Acknowledgments: Santosh Kumar Tadakamadla is supported by a National Health and Medical Research Council Early Career Fellowship, Australia.

Conflicts of Interest: The authors declare no conflict of interest.

\section{References}

1. de Souza, H.S.; Fiocchi, C. Immunopathogenesis of IBD: Current state of the art. Nat. Rev. Gastroenterol. Hepatol. 2016, 13, 13-27. [CrossRef]

2. Fróes, R.S.B.; Carvalho, A.T.P.; Carneiro, A.J.d.V.; de Barros Moreira, A.M.D.; Moreira, J.L.P.; de Souza, H.S. The socio-economic impact of work disability due to inflammatory bowel disease in Brazil. Eur. J. Health Econ. 2018, 19, 463-470. [CrossRef]

3. Froes, R.d.S.B.; Carvalho, A.T.P.; Carneiro, A.J.d.V.; de Barros Moreira, A.M.D.; Moreira, J.L.P.; de Souza, H.S. Worldwide incidence and prevalence of inflammatory bowel disease in the 21st century: A systematic review of population-based studies. Lancet 2017, 390, 2769-2778.

4. Zhang, Y.; Qiao, D.; Chen, R.; Zhu, F.; Gong, J.; Yan, F. The Association between Periodontitis and Inflammatory Bowel Disease: A Systematic Review and Meta-analysis. BioMed Res. Int. 2021, 2021, 1-8. [CrossRef]

5. Tan, C.X.W.; Brand, H.S.; Kalender, B.; De Boer, N.K.H.; Forouzanfar, T.; de Visscher, J.G.A.M. Dental and periodontal disease in patients with inflammatory bowel disease. Clin. Oral Investig. 2021, 25, 5273-5280. [CrossRef] [PubMed]

6. Lorenzo-Pouso, A.I.; Castelo-Baz, P.; Rodriguez-Zorrilla, S.; Perez-Sayans, M.; Vega, P. Association between periodontal disease and inflammatory bowel disease: A systematic review and me-ta-analysis. Acta Odontol. Scand. 2021, 79, 344-353. [CrossRef]

7. Papageorgiou, S.N.; Hagner, M.; Nogueira, A.V.B.; Franke, A.; Jäger, A.; Deschner, J. Inflammatory bowel disease and oral health: Systematic review and a meta-analysis. J. Clin. Periodontol. 2017, 44, 382-393. [CrossRef] [PubMed]

8. Agossa, K.; Roman, L.; Gosset, M.; Yzet, C.; Fumery, M. Periodontal and dental health in inflammatory bowel diseases: A systematic review. Expert Rev. Gastroenterol. Hepatol. 2021, 1-15. [CrossRef] [PubMed] 
9. Papapanou, P.N.; Sanz, P.; Buduneli, N.; Dietrich, T.; Feres, M.; Fine, D.H.; Flemming, T.F.; Garcia, R.; Giannobile, W.V.; Graziani, F.; et al. Periodontitis: Consensus report of workgroup 2 of the 2017 World Workshop on the Classification of Periodontal and Peri-Implant Diseases and Conditions. J. Periodontol. 2018, 89, S173-S182. [CrossRef] [PubMed]

10. Bernabe, E.; Marcenes, W.; Hernandez, C.; Bailey, J.; Abreu, L.; Alipour, V.; Amini, S.; Arabloo, J.; Arefi, Z.; Arora, A.; et al. Global, Regional, and National Levels and Trends in Burden of Oral Conditions from 1990 to 2017: A Systematic Analysis for the Global Burden of Disease 2017 Study. J. Dent. Res. 2020, 99, 362-373. [CrossRef]

11. Vos, T.; Abajobir, A.A.; Abate, K.H.; Abbafati, C.; Abbas, K.M.; Abd-Allah, F.; Abdulkader, R.S.; Abdulle, A.M.; Abebo, T.A.; Abera, S.F.; et al. Global, regional, and national incidence, prevalence, and years lived with disability for 328 diseases and injuries for 195 countries, 1990-2016: A systematic analysis for the Global Burden of Disease Study 2016. Lancet 2017, 390, 1211-1259. [CrossRef]

12. Cekici, A.; Kantarci, A.; Hasturk, H.; Van Dyke, T.E. Inflammatory and immune pathways in the pathogenesis of periodontal disease. Periodontology 2000 2013, 64, 57-80. [CrossRef]

13. Van Dyke, T.E.; Bartold, P.M.; Reynolds, E.C. The Nexus between Periodontal Inflammation and Dysbiosis. Front. Immunol. 2020, 11, 511. [CrossRef]

14. Byrd, K.M.; Gulati, A.S. The Gum-Gut Axis in Inflammatory Bowel Diseases: A Hypothesis-Driven Review of Associations and Advances. Front. Immunol. 2021, 12, 620124. [CrossRef]

15. Fujino, S.; Andoh, A.; Bamba, S.; Ogawa, A.; Hata, K.; Araki, Y.; Bamba, T.; Fujiyama, Y. Increased expression of interleukin 17 in inflammatory bowel disease. Gut 2003, 52, 65-70. [CrossRef] [PubMed]

16. Garber, A.; Regueiro, M. Extraintestinal Manifestations of Inflammatory Bowel Disease: Epidemiology, Etiopathogenesis, and Management. Curr. Gastroenterol. Rep. 2019, 21, 31. [CrossRef] [PubMed]

17. Komatsu, M.; Kobayashi, D.; Saito, K.; Furuya, D.; Yagihashi, A.; Araake, H.; Tsuji, N.; Sakamaki, S.; Niitsu, Y.; Watanabe, N. Tumor necrosis factor-alpha in serum of patients with inflammatory bowel disease as measured by a highly sensitive immuno-PCR. Clin. Chem. 2001, 47, 1297-1301. [CrossRef] [PubMed]

18. Hajishengallis, G.; Chavakis, T. Local and systemic mechanisms linking periodontal disease and inflammatory comorbidities. Nat. Rev. Immunol. 2021, 21, 426-440. [CrossRef]

19. Loos, B.G. Systemic Markers of Inflammation in Periodontitis. J. Periodontol. 2005, 76, 2106-2115. [CrossRef]

20. Paraskevas, S.; Huizinga, J.D.; Loos, B.G. A systematic review and meta-analyses on C-reactive protein in relation to periodontitis. J. Clin. Periodontol. 2008, 35, 277-290. [CrossRef] [PubMed]

21. Lira-Junior, R.; Figueredo, C.M. Periodontal and inflammatory bowel diseases: Is there evidence of complex pathogenic interactions? World J. Gastroenterol. 2016, 22, 7963-7972. [CrossRef]

22. Kitamoto, S.; Nagao-Kitamoto, H.; Jiao, Y.; Gillilland, M.G.; Hayashi, A.; Imai, J.; Sugihara, K.; Miyoshi, M.; Brazil, J.C.; Kuffa, P.; et al. The Intermucosal Connection between the Mouth and Gut in Commensal Pathobiont-Driven Colitis. Cell 2020, 182, 447-462.e14. [CrossRef]

23. Baima, G.; Massano, A.; Squillace, E.; Caviglia, G.P.; Buduneli, N.; Ribaldone, D.G.; Aimetti, M. Shared microbiological and immunological patterns in periodontitis and IBD: A scoping review. Oral Dis. 2021. [CrossRef] [PubMed]

24. Moher, D.; Liberati, A.; Tetzlaff, J.; Altman, D.G. The PRISMA Group Preferred Reporting Items for Systematic Reviews and Meta-Analyses: The PRISMA Statement. PLoS Med. 2009, 6, e1000097. [CrossRef]

25. Zhao, D.; Khawaja, A.T.; Jin, L.; Li, K.-Y.; Tonetti, M.; Pelekos, G. The directional and non-directional associations of periodontitis with chronic kidney disease: A systematic review and meta-analysis of observational studies. J. Periodontal Res. 2018, 53, 682-704. [CrossRef] [PubMed]

26. Chambrone, L.; Guglielmetti, M.R.; Pannuti, C.M.; Chambrone, L.A. Evidence grade associating periodontitis to preterm birth and/or low birth weight: I. A systematic review of prospective cohort studies. J. Clin. Periodontol. 2011, 38, 795-808. [CrossRef]

27. Van Dyke, T.E.; Dowell, V.R.; Offenbacher, S.; Snyder, W.; Hersh, T. Potential role of microorganisms isolated from periodontal lesions in the pathogenesis of inflammatory bowel disease. Infect. Immun. 1986, 53, 671-677. [CrossRef] [PubMed]

28. Figueredo, C.M.; Brito, F.; Barros, F.C.; Menegat, J.S.B.; Pedreira, R.R.; Fischer, R.G.; Gustafsson, A. Expression of cytokines in the gingival crevicular fluid and serum from patients with inflammatory bowel disease and untreated chronic periodontitis. J. Periodontal Res. 2011, 46, 141-146. [CrossRef]

29. Schmidt, J.; Weigert, C.; Leuschner, H.; Raddatz, R.; Haak, R.F.; Mauseberg, T.; Kottman, G.; Schmaltz, D.; Ziebolz, D. Active matrix metalloproteinase- 8 and periodontal bacteria-interlink between periodontitis and inflammatory bowel disease? J. Periodontol. 2018, 89, 699-707. [CrossRef]

30. Figueredo, C.M.; Nunes, J.G.; Mello-Neto, J.M.; Carvalho, A.T.; Ipe, D.S. Higher salivary expression of S100A12 in patients with ulcerative colitis and chronic periodontitis. Eur. J. Gastroenterol. Hepatol. 2021, 33, 116-117. [CrossRef]

31. Figueredo, C.; Martins, A.; Lira-Junior, R.; Menegat, J.; Carvalho, A.T.P.; Fischer, R.; Gustafsson, A. Activity of inflammatory bowel disease influences the expression of cytokines in gingival tissue. Cytokine 2017, 95, 1-6. [CrossRef] [PubMed]

32. Menegat, J.S.B.; Lira-Junior, R.; Siqueira, M.A.; Brito, F.; Carvalho, A.T.P.; Fischer, R.G.; Figueredo, C.M. Cytokine expression in gingival and intestinal tissues of patients with periodontitis and inflammatory bowel disease: An exploratory study. Arch. Oral Biol. 2016, 66, 141-146. [CrossRef]

33. Deng, J.; Yu, X.-Q.; Wang, P.-H. Inflammasome activation and Th17 responses. Mol. Immunol. 2019, 107, 142-164. [CrossRef] [PubMed] 
34. Ludwiczek, O.; Kaser, A.; Novick, D.; Dinarello, C.A.; Rubeisten, M.; Tilg, H. Elevated systemic levels of free interleukin-18 (IL-18) in patients with Crohn's disease. Eur. Cytokine Net. 2005, 16, 27-33.

35. Roberts, H.M.; Ling, M.R.; Insall, R.; Kalna, G.; Spengler, J.; Grant, M.; Chapple, I.L. Impaired neutrophil directional chemotactic accuracy in chronic periodontitis patients. J. Clin. Periodontol. 2015, 42, 1-11. [CrossRef]

36. Gui, X.; Li, J.; Ueno, A.; Iacucci, M.; Qian, J.; Ghosh, S. Histopathological Features of Inflammatory Bowel Disease are Associated with Different CD4+ T Cell Subsets in Colonic Mucosal Lamina Propria. J. Crohn's Coliti 2018, 12, 1448-1458. [CrossRef]

37. Bastos, M.; Lima, J.; Vieira, P.; Mestnik, M.; Faveri, M.; Duarte, P. TNF- $\alpha$ and IL-4 levels in generalized aggressive periodontitis subjects. Oral Dis. 2009, 15, 82-87. [CrossRef] [PubMed]

38. Holmström, S.B.; Lira-Junior, R.; Zwicker, S.; Majster, M.; Gustafsson, A.; Åkerman, S.; Klinge, B.; Svensson, M.; Boström, E.A. MMP-12 and S100s in saliva reflect different aspects of periodontal inflammation. Cytokine 2018, 113, 155-161. [CrossRef]

39. Leibur, E.; Tuhkanen, A.; Pintson, U.; Söder, P.O. Prostaglandin E2 levels in blood plasma and in crevicular fluid of advanced periodontitis patients before and after surgical therapy. Oral Dis. 2008, 5, 223-228. [CrossRef]

40. Zhang, L.; Li, X.; Yan, H.; Huang, L. Salivary matrix metalloproteinase (MMP)-8 as a biomarker for periodontitis: A PRISMAcompliant systematic review and meta-analysis. Medicine 2018, 97, e9642. [CrossRef]

41. Luzina, I.G.; Keegan, A.D.; Hellen, N.M.; Rook, G.A.W.; Shea-Donohue, T.; Atamas, S.P. Regulation of inflammation by interleukin-4: A review of alternatives. J. Leukoc. Biol. 2012, 92, 753-764. [CrossRef] [PubMed]

42. Lazarski, C.A.; Ford, J.; Katzman, S.D.; Rosenberg, A.F.; Fowell, D.J. IL-4 Attenuates Th1-Associated Chemokine Expression and Th1 Trafficking to Inflamed Tissues and Limits Pathogen Clearance. PLoS ONE 2013, 8, e71949. [CrossRef]

43. Karttunnen, R.; Breese, E.J.; Walker-Smith, J.A.; Macdonald, T.T. Decreased mucosal interleukin-4 (IL-4) production in gut inflammation. J. Clin. Pathol. 1994, 47, 1015-1018. [CrossRef]

44. Dey, I.; Lejeune, M.; Chadee, K. Prostaglandin E2receptor distribution and function in the gastrointestinal tract. Br. J. Pharmacol. 2006, 149, 611-623. [CrossRef] [PubMed]

45. Koelink, P.J.; Overbeek, S.A.; Braber, S.; Morgan, M.E.; Henricks, P.A.J.; Roda, M.A.; Verspaget, H.W.; Wolfkamp, S.C.; Velde, A.A.T.; Jones, C.W.; et al. Collagen degradation and neutrophilic infiltration: A vicious circle in inflammatory bowel disease. Gut 2013, 63, 578-587. [CrossRef] [PubMed]

46. Kaiser, T.; Langhorst, J.; Wittkowski, H.; Becker, K.; Friedrich, A.W.; Rueffer, A.; Dobos, G.J.; Roth, J.; Foell, D. Faecal S100A12 as a non-invasive marker distinguishing inflammatory bowel disease from irritable bowel syndrome. Gut 2007, 56, 1706-1713. [CrossRef]

47. Leach, S.; Yang, Z.; Messina, I.; Song, C.; Geczy, C.L.; Cunningham, A.M.; Day, A.S. Serum and mucosal S100 proteins, calprotectin (S100A8/S100A9) and S100A12, are elevated at diagnosis in children with inflammatory bowel disease. Scand. J. Gastroenterol. 2007, 42, 1321-1331. [CrossRef]

48. Naber, A.H.J.; De Jong, D.J. Assessment of disease activity in inflammatory bowel disease; relevance for clinical trials. Neth. J. Med. 2003, 61, 105-110.

49. Lo, C.-H.; Nguyen, L.H.; Wu, K.; Ogino, S.; Chan, A.T.; Giovannucci, E.L.; Song, M. Periodontal Disease, Tooth Loss, and Risk of Serrated Polyps and Conventional Adenomas. Cancer Prev. Res. 2020, 13, 699-706. [CrossRef]

50. Nwizu, N.; Wactawski-Wende, J.; Genco, R.J. Periodontal disease and cancer: Epidemiologic studies and possible mechanisms. Periodontology 2000 2020, 83, 213-233. [CrossRef]

51. Michaud, D.S.; Fu, Z.; Shi, J.; Chung, M. Periodontal Disease, Tooth Loss, and Cancer Risk. Epidemiol. Rev. 2017, 39, 49-58. [CrossRef] [PubMed]

52. Mantovani, A.; Allavena, P.; Sica, A.; Balkwill, F. Cancer-related inflammation. Nature 2008, 454, 436-444. [CrossRef] [PubMed] 